Meta

Journal des traducteurs

Translators' Journal

\title{
Hommage à Jean-Paul Vinay (1910-1999)
}

\section{André Clas}

Volume 44, numéro 2, juin 1999

URI : https://id.erudit.org/iderudit/002305ar

DOI : https://doi.org/10.7202/002305ar

Aller au sommaire du numéro

Éditeur(s)

Les Presses de l'Université de Montréal

ISSN

0026-0452 (imprimé)

1492-1421 (numérique)

Découvrir la revue

Citer ce document

Clas, A. (1999). Hommage à Jean-Paul Vinay (1910-1999). Meta, 44(2), 215-216.

https://doi.org/10.7202/002305ar d'utilisation que vous pouvez consulter en ligne.

https://apropos.erudit.org/fr/usagers/politique-dutilisation/ 


\section{Hommage à Jean-Paul Vinay (1910-1999)}

Jean-Paul Vinay vient de nous quitter définitivement. Phonéticien, linguiste, polyglotte, pédagogue, dessinateur, musicien et aussi traducteur, Jean-Paul Vinay était fort connu dans le monde universitaire de la traduction. II a dirigé pendant de nombreuses années la section de linguistique, puis le département de linguistique de l'Université de Montréal où il a mis en place, outre un programme de formation en linguistique, des cours de traduction et d'interprétation. Ses préoccupations théoriques et pratiques en linguistique et en traduction l'ont tout naturellement amené à vouloir mieux «structurer » l'enseignement, à promouvoir la formation permanente et à participer à l'organisation de la profession de traducteur au Canada. On comprend donc que dès 1955, on voit apparaître la publicité pour un ouvrage Manuel de Traduction (français et anglais). Traité pratique de stylistique comparée. Et en 1958, paraît en effet aux éditions Didier à Paris et Beauchemin à Montréal, la Stylistique comparée du français et del'anglais. M éthode de traduction de Jean-Paul Vinay et de Jean Darbelnet. Ce livre, bien connu dans tous les pays (l'ouvrage vient d'être traduit en anglais), est encore utilisé de nos jours. II a connu plusieurs rééditions et révisions et a servi souvent de «manuel » de base à des générations d'étudiants en linguistique et en traduction. Inspiré des travaux de Charles Bally et d'Albert Malblanc, ce manuel a mis en valeur la nécessité de passer de «l'art » à la «systématisation » dans l'enseignement de la traduction. On ne peut que souligner à nouveau l'apport de ce manuel à la progression de la réflexion dans ce domaine que l'on appelle de nos jours la traductologie (Ü bersetzungswissenschaft).

En octobre 1955, paraissait à M ontréal le premier numéro du bulletin de l'Association canadienne des traducteurs diplômés, the Canadian Association of Certified Translators, ayant comme titre: Journal des Traducteurs/Translators' Journal. Dès le numéro 5 du premier volume, en octobre 1956, Jean-Paul Vinay, pour promouvoir les études de traduction et donner aussi au bulletin la stabilité voulue, en assure la direction et transporte le secrétariat à la section de linguistique de l'Université de Montréal. Pendant plus de dix ans, il a dirigé et animé cette revue. La revue a grandi, a changé et elle a pris, en 1966, avec le volume 11, le nom de META. En septembre 1966, Jean-Paul Vinay a abandonné la direction de la revue. II a cependant, jusqu'à la veille de sa mort, gardé le contact avec la revue et si les circonstances le justifiaient, il ne manquait pas de jouer pleinement son rôle de membre correspondant.

Toujours présent, toujours vigilant, Jean-Paul Vinay a été un des grands «déve loppeurs» de la traduction au Canada. Notre reconnaissance lui est acquise. Ce numéro se veut être un hommage à l'homme et à son œuvre.

Merci Jean-Paul Vinay. 